\title{
Therapeutic Applications of Coconut Water Mitigates Diabetes Mellitus in Oryctolagus cuniculus (Rabbit)
}

\author{
Shahab Uddin ${ }^{1 \$}$, Imdad Ali1\$, Mazhar Hassan"1 Laila Hamayun¹, Uroba Ali ${ }^{1}$, Shah Saud ${ }^{1}$, Ibrahim Khan ${ }^{1}$, \\ Waqas Ahmad", Abdul Bari Shah², Amir Zeb*3 and Ayaz Ali Khan*1 \\ ${ }^{1}$ Department of Biotechnology, University of Malakand, Pakistan \\ ${ }^{2}$ Department of Chemistry, University of Malakand, Pakistan \\ ${ }^{3}$ Department of Biotechnology, Quaid-i-Azam University, Pakistan \\ ${ }^{\$}$ These authors contributed equaliy to this work \\ *Corresponding author: Ayaz Ali Khan, Department of Biotechnology, Charkdara, Dir (L), Khyber Pakhtunkhwa, Pakistan \\ Amir Zeb, Department of Biotechnology, Islamabad, Pakistan
}

\section{ARTICLE INFO}

Received: 閂 March 25, 2019

Published: 猘 April 01, 2019

Citation: Shahab Uddin, Imdad Ali, Mazhar Hassan, Laila Hamayun, Uroba Ali, Shah Saud, Ibrahim Khan, Waqas Ahmad, Abdul Bari Shah, Amir Zeb, Ayaz Ali Khan. Therapeutic Applications of Coconut Water Mitigates Diabetes Mellitus in Oryctolagus cuniculus (Rabbit). Biomed J Sci \& Tech Res 16(4)2019. BJSTR. MS.ID.002884.

Keywords: Coconut Water; Diabetes; Streptozotocin; Biochemical parameters
ABSTRACT

Diabetes mellitus (DM) is a pandemic disease and causes significant contribution to human mortality across the globe. Since, natural products have been proved to be safe and effective remedies in human healthcare practice; therefore, the present study has investigated the anti-diabetic potential of coconut water against the diabetic rabbits. Rabbits were intoxicated with streptozotocin ( $80 \mathrm{mg} / \mathrm{kg}$ body weight) and diabetes mellitus was induced. To counteract initial hypoglycemia, $10 \%$ of glucose was administrated in drinking water for 24 hours. One group was kept as negative control, another was diabetic and un-medicated control, two groups were fed with coconut water dose $2.2 \mathrm{~g} / \mathrm{kg}$ and $4.1 \mathrm{~g} / \mathrm{kg}$, and last group was medicated with Metformin. Several analyses such as body weight, physical activities, urination, and different biochemical properties and characterization of blood samples were performed. The intoxicated rabbits were characterized by weight loss, frequent urination, sluggish physical activities, low level of high-density lipoprotein, and elevated levels of blood glucose, cholesterol, and triglyceride. Upon administration of coconut water at a dose rate of $2.2 \mathrm{~g} / \mathrm{kg}$ and $4.1 \mathrm{~g} / \mathrm{kg}$ for two weeks, all the parameters became normal and/or near to normal when compared to positive control. Therefore, we recommend that coconut water can be developed as a nutraceutical or functional food for the management of diabetes and its associated complications.

Abbreviations: SGOT: Serum the Level of Glutamic-Oxaloacetic Transaminase; SGPT: Serum Glutamic Pyruvic Transaminase; DM: Diabetes Mellitus; WHO: World Health Organization; OAAs: Oral Anti-Diabetic Agents; HDL: High Density Lipoprotein

\section{Introduction}

Diabetes mellitus (DM) is an epidemic disease and causes severe problem to human health [1]. By definition, diabetes mellitus is a group of metabolic imbalances, results in hyperglycemia, which is either caused by abnormal production of insulin or its harmful physiology [2]. Diabetic patients are at more risk to cardiac, peripheral arterial and cerebrovascular diseases [2,3]. The chronic hyperglycemia of diabetes is associated with long-term damage, dysfunction, and failure of various organs including eyes, kidneys, nerves, heart, and blood vessels [4]. DM also disturbs function of liver, therefore, in blood serum the level of glutamic-oxaloacetic transaminase (SGOT) and Serum Glutamic Pyruvic Transaminase
(SGPT) increases [5]. There is usually persistent thirst, polyuria, blurred vision, and weight loss followed by ketoacidosis or nonketotic hyperosmolar condition that leads to stupor, coma and, if untreated causes death [6]. In 1993, the World Health Organization (WHO) Diabetes reporting group published global estimates for the prevalence of diabetes from 75 communities in 32 countries [7].

Worldwide, the prevalence rate of obesity, diabetes, and other metabolic syndromes is high $[8,9]$. There have been several previous estimates of the number of persons with diabetes. Prevalence of diabetes among adults (age 20-79 years) will increase to $7.7 \%$ (439 million) of the world population by 2030 . This estimation is 
alarmingly high for developing countries where diabetes patients will increase to $69 \%$ by 2030 [10]. According to World Health Organization (WHO), diabetes will be the 7th leading cause of death in 2030 [11]. Currently, Pakistan occupies 7th position of high-risk diabetes-suffered countries [12]. The current prevalence of type 2 diabetes (T2D) in Pakistan is $11.77 \%$ [13]. Furthermore, according to National Survey (2016-17), 26\% of Pakistan population is suffering from diabetes. Therefore, prevention of diabetes mellitus needs serious attention in health policy. By far the most popular approach to treat T2D is glycemic control in an attempt to reduce complications and death. In the past, several drugs for T2D including oral anti-diabetic agents (OAAs), insulin, and incretin-based drugs have been developed.

For instance, sulfonylurea-type drugs, insulin sensitizers such as TZDs (e.g., rosiglitazone and pioglitazone) and a biguanide, metformin, can directly lower insulin resistance and, subsequently, blood glucose. Glucose (re)absorption is viewed as an alternative way to lower blood glucose level. Inhibitors of Sglt 2 and glucosidase such asdapagliflozin, empagliflozin, and acarbose, inhibit the activity of sodium-glucose cotransporter- 2 and glucosidases, respectively. Such inhibition leads to decrease glucose (re)absorption via the renal tubules and the intestine, respectively $[14,15]$. The available anti-diabetic drugs have limited rolesand cause serious sideeffects. For instance, metformin [16], pioglitazone [17], and SGLT-2 inhibitors [18] cause lactic acidosis, edema and heart failure, and dehydration, urinary and genital infections,respectively. Lowering blood glucose and lipid profiles by using natural products of plant origin as a possible therapeutic measure has become a promising scientific investigation. It has been reported that essential oils may be effective against type 2 diabetes mellitus. The daily consumption of olive oil had positive effect on fasting blood glucose and lipid profiles of healthy controls [19]

Experimental studies have shown that Hibiscus rosasinensis Linn. ethanol flower extracthas positive effect on blood glucose and lipid profile in streptozotocin induced diabetes in rats [20]. Aloe vera gel extract has hypoglycemic, hypotriglyceridemic properties in STZ-diabetic rats [21]. The natural Egyptian Morus alba root bark extracthas protective effects in diabetes by decreasing glucose level, moderate lipid peroxidation, and preservation of pancreatic $\beta$ cell integrity [22]. CW is a rich source of essential metabolites including sugars, sugar alcohols, vitamin C,folic acid,free amino acids, phytohormones (auxin, cytokinin), enzymes (acid phosphatase, catalase, dehydrogenase, diastase, peroxidase, RNA -polymerases) and growth promoting factors [23]. Quantitative difference in the composition of the active components available in coconut water are $95.3 \%$ water, $0.005 \%$ nitrogen, $0.56 \%$ Phosphoric acid, $0.25 \%$ Potassium, $0.69 \%$ Calcium oxide, 0.59\% Magnesium oxide, $0.5 \%$ Iron, $0.8 \%$ reducing sugar and a total sugar of $2.08 \%$ [24]. Since, the coconut water has several medicinal properties such as hypocholesterolemic, antihypertensive, cardio protective, hepatoprotective, and hypolipidemic properties [25,26]. Therefore, the current study has evaluated the therapeutic potential of CW against the diabetic rabbits.

\section{Materials and Methods}

\section{Selection of Animals}

Oryctolagus cuniculus (Rabbit) was selected as experimental animals. Rabbits were purchased from local markets and divided into several groups on the basis of their body weights.

\section{Induction of Diabetes Mellitus (DM)}

Streptozotocin was used for the induction of diabetes mellitus in rabbits. The rabbits were made diabetic by injecting streptozotocin via peritoneum route [27]. Streptozotocin dose was administrated body weight dependent. To counteract initial hypoglycemia, glucose was given orally, also $10 \%$ glucose was provided in drinking water for next 24 hours [28].

\section{Drug Administration}

a. Group A was medicated with coconut water at the dose rate of $2.2 \mathrm{~g} / \mathrm{kg}$ body weight.

b. Group B was medicated with coconut water at the dose rate of $4.1 \mathrm{~g} / \mathrm{kg}$ body weight.

c. Group C was kept as null control without any treatment.

d. Group D was kept as negative control (diabetic but unmedicated).

e. Group E was considered as positive control and medicated with Glucophage (Metformin $\mathrm{HCl}$ ) at the dose rate of $14 \mathrm{mg} / \mathrm{kg}$ body weight.

f. Drug administration was continued for regular 15 days after confirmation of diabetes mellitus.

\section{Collection of Blood Samples}

Blood samples were collected from all the groups with the following schedule; Day zero, day 03, day 08, day 13, and day 18. Blood samples were collected, stored in slant position and serum was oozed out upon clotting. Serum was collected in falcon tubes and was analyzed for glucose, triglyceride, cholesterol, HDL and LDL levels.

Analysis of biochemical parameters. Blood samples were analyzed for different parameters using their respective standard available kits (Semi Auto Chemistry Analyzer).

\section{Statistical Analysis}

The results obtained were analyzed statistically. Mean and standard deviation were determined. All the values of different groups were compared at different days using ANOVA. Online software, Prism, and Demo v05 were used for statistical analysis (www.graphpad.com). 


\section{Results}

\section{Induction of Diabetes Mellitus}

All the rabbits of group A, B, D and E were intoxicated with streptozotocin $(80 \mathrm{mg} / \mathrm{kg})$. Diabetes mellitus was confirmed on day 3rd of the experiment. Our results suggested that diabetic-induced rabbits lost their body weight (Table 1). Two groups (A and B) were treated with coconut water at dose rate of $2.2 \mathrm{~g} / \mathrm{kg}$ and $4.1 \mathrm{~g} /$

Table 1: Time-scale analysis of body weight of rabbits $(n=3)$. $\mathrm{kg}$, while, one group (E) was medicated with $14 \mathrm{mg} / \mathrm{kg}$ metformin $\mathrm{HCl}$. Our results observed significant increase $(\mathrm{P}<0.0001)$ in the body weight of diabetic treated groups (Table 1). Upon treatment of diabetic rabbits with $\mathrm{CW}$, it was observed that the treated rabbits were gaining body weight (Table 1). Conversely, significant decrease $(\mathrm{P}<0.0001)$ was observed in the body weight of positive control (Table 1). Our results observed that that coconut water and metformin increase the body weight in diabetic groups (Table 1).

\begin{tabular}{|c|c|c|c|c|c|c|c|c|c|}
\hline \multirow{4}{*}{ Groups } & \multirow{4}{*}{ Medication } & \multicolumn{8}{|c|}{ Weight of rabbits in gram $(n=3)$} \\
\hline & & \multicolumn{8}{|c|}{$(\mathrm{M} \# \pm \mathrm{SD} \$)$} \\
\hline & & \multicolumn{8}{|c|}{ Days } \\
\hline & & $\mathbf{0}$ & 3 & 6 & 8 & 11 & 13 & 15 & 18 \\
\hline \multirow{2}{*}{ A } & $\mathrm{CW}^{*}$ & $563 \pm 3.79$ & $553 \pm 3.21$ & $543 \pm 3.51$ & $544 \pm 2.08$ & $547 \pm 1.00$ & $554 \pm 2.65$ & $561 \pm 3.06$ & $574 \pm 2.52$ \\
\hline & $2.2 \mathrm{~g} / \mathrm{kg}$ & & & & & & & & \\
\hline \multirow{2}{*}{ B } & $\mathrm{CW}$ & $532 \pm 1.53$ & $519 \pm 1.00$ & $507 \pm 2.08$ & $510 \pm 3.21$ & $513 \pm 2.65$ & $520 \pm 3.00$ & $533 \pm 3.21$ & $542 \pm 2.08$ \\
\hline & $4.1 \mathrm{~g} / \mathrm{kg}$ & & & & & & & & \\
\hline $\mathrm{C}$ & $\mathrm{NC}$ & $540 \pm 2.52$ & $542 \pm 1.00$ & $540 \pm 2.08$ & $540 \pm 3.00$ & $540 \pm 2.52$ & $543 \pm 2.08$ & $540 \pm 3.61$ & $541 \pm 2.65$ \\
\hline $\mathrm{D}$ & РС $\Psi$ & $569 \pm 2.08$ & $560 \pm 3.21$ & $557 \pm 1.00$ & $549 \pm 2.00$ & $539 \pm 2.08$ & $534 \pm 2.65$ & $530 \pm 1.53$ & $523 \pm 2.52$ \\
\hline $\mathrm{E}$ & Metformin $14 \mathrm{mg} / \mathrm{kg}$ & $550 \pm 1.53$ & $548 \pm 2.65$ & $537 \pm 3.21$ & $537 \pm 2.00$ & $541 \pm 2.52$ & $550 \pm 1.53$ & $551 \pm 2.65$ & $556 \pm 1.00$ \\
\hline
\end{tabular}

Note: \#M: Mean

\$SD: Standard deviation

${ }^{*} \mathrm{CW}$ : Coconut water

NC: Negative control

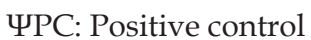

\section{Analysis of Blood Glucose Level}

Blood glucose level of all rabbits was analyzed prior to exposure to STZ. The glucose levels were $160 \pm 2.52,161 \pm 2.08$, $161 \pm 2.08,161 \pm 2.61$, and $161 \pm 1.53 \mathrm{mg} / \mathrm{dl}$ of group A, B, C, D, and E, respectively (Figures $1 \& 2$ ). After intoxication with STZ (80mg/ $\mathrm{kg}$ ), diabetes was further confirmed by blood glucose analysis. Blood glucose levels were found $287 \pm 3.00,290 \pm 3.21,269 \pm 3.61$, and $260 \pm 2.00 \mathrm{mg} / \mathrm{dl}$ for group A, B, D, and E, respectively (Figures $1 \& 2)$. Our results observed elevated glucose level in all the diabetic rabbits as compared to negative control $(160 \pm 1.53 \mathrm{mg} / \mathrm{dl})$. Our findings suggested that administration of CW to diabetic groups at dose rate of $2.2 \mathrm{~g} / \mathrm{kg}$ and $4.1 \mathrm{~g} / \mathrm{kg}$ for eight days decreased the blood glucose level to $254 \pm 3.61$ and $247 \pm 2.00 \mathrm{mg} / \mathrm{dl}$, respectively. Moreover, the glucose level of metformin-treated group dropped down to $229 \pm 1.53 \mathrm{mg} /$ dl. Furthermore, on day 13th and 18th, further decrease was observed in the glucose level of CW-treated groups A and B to $188 \pm 2.00$ and $187 \pm 2.00 \mathrm{mg} / \mathrm{dl}$ and $163 \pm 1.53$ and $162 \pm 1.53 \mathrm{mg} / \mathrm{dl}$, respectively (Figures 1 \& 2). Metformin also decreased the glucose level significantly. Hence, our findings demonstrated a significant difference $(\mathrm{P}<0.0001)$ in the blood glucose level of CW-treated and -untreated diabetic rabbits.

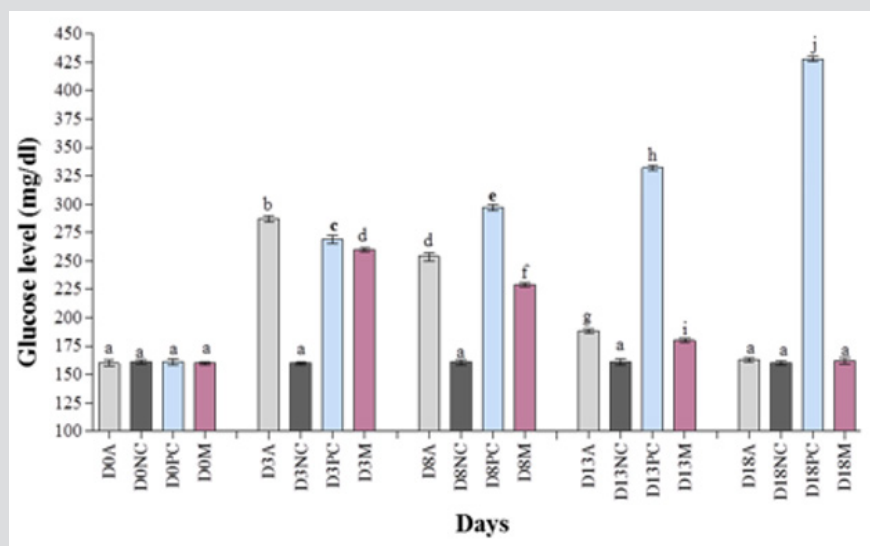

Figure 1: Blood glucose level of rabbits medicated with $\mathrm{CW}$ at dose rate of $2.2 \mathrm{~g} / \mathrm{kg}$. 


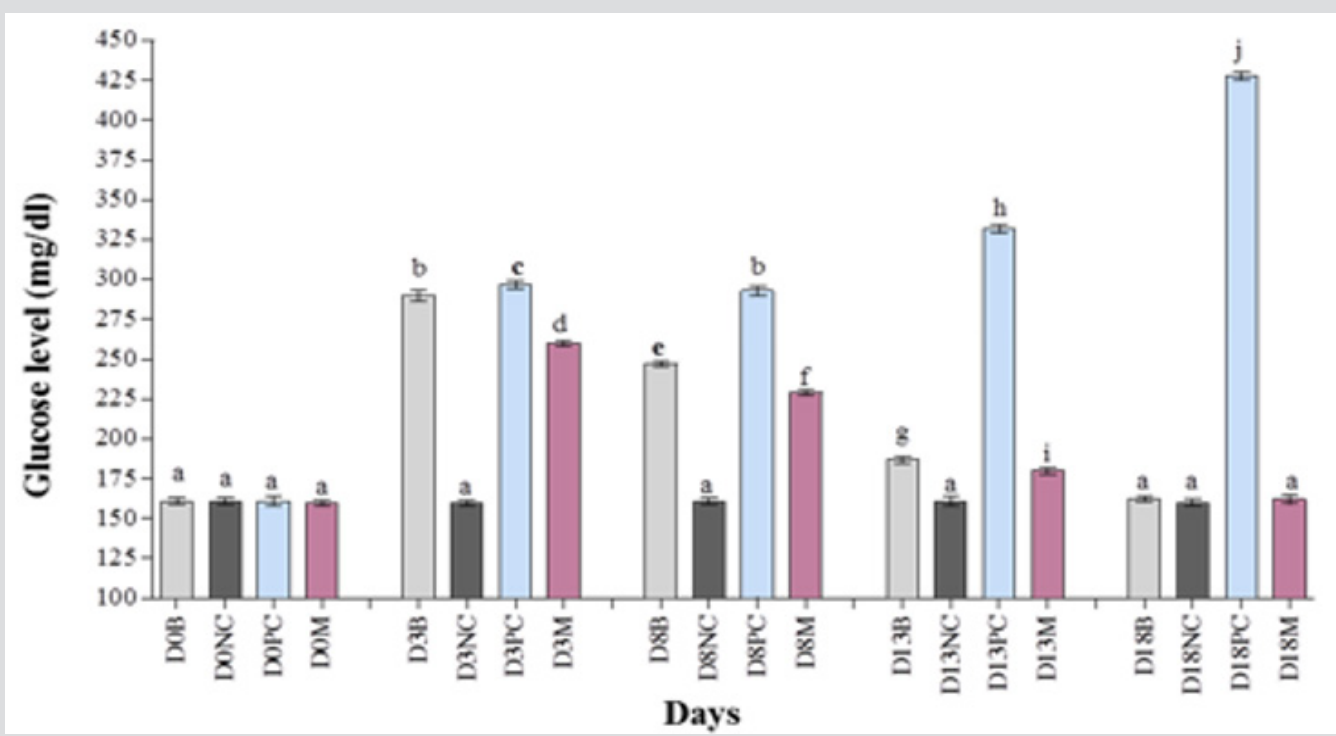

Figure 2: Blood glucose level of rabbits medicated with $\mathrm{CW}$ at dose rate of $4.1 \mathrm{~g} / \mathrm{kg}$.

\section{Analysis of Blood Cholesterol Level}

Before induction of diabetes, blood cholesterol level was determined and observed that group A, B, C, D, and E has blood cholesterol level of $55.0 \pm 2.65,55.7 \pm 2.52,57.7 \pm 2.08,57.3 \pm 3.79$, and $54.7 \pm 2.52 \mathrm{mg} / \mathrm{dl}$, respectively (Figures $3 \mathrm{~A} \& 4 \mathrm{~A}$ ). Our results observed that upon induction of diabetes, cholesterol level was increased to $81.7 \pm 3.79,80.3 \pm 3.21,81.2 \pm 2.65$, and $80.0 \pm 1.00 \mathrm{mg} / \mathrm{dl}$ as compared to negative control $62.0 \pm 2.65 \mathrm{mg} / \mathrm{dl}$ (Figures 3A \& 4A) which show significant difference in all diabetic groups. Thereafter, the diabetic group $\mathrm{A}$ and $\mathrm{B}$, were treated with CW at dose rate of $2.2 \mathrm{~g} /$ $\mathrm{kg}$ and $4.1 \mathrm{~g} / \mathrm{kg}$, and group E were treated with metformin $14 \mathrm{mg} / \mathrm{kg}$. Our analysis of blood samples on day 8th observed that cholesterol level was reduced to $74.7 \pm 2.08,73.0 \pm 2.00$ and $70.7 \pm 2.08 \mathrm{mg} /$ $\mathrm{dl}$ in medicated group. Moreover, further decrease was observed at day 13th to $68.3 \pm 1.53$ and $66.3 \pm 1.53$ in the cholesterol level of CW-treated groups A and B and in metformin-administrated group $65.0 \pm 2.00 \mathrm{mg} / \mathrm{dl}$. Further reduction was noted at day $18^{\text {th }}$ in the cholesterol level to $58.0 \pm 1.00,57.0 \pm 1.00$, and $56.3 \pm 3.06 \mathrm{mg} / \mathrm{dl}$ of CW-treated groups A and B and metformin-administrated group. Therefore, we suggested that $\mathrm{CW}$ at the dose rate of 2.2 and $4.1 \mathrm{~g} /$ kg leads to decrease in cholesterol level (Figures 3A \& 4A).
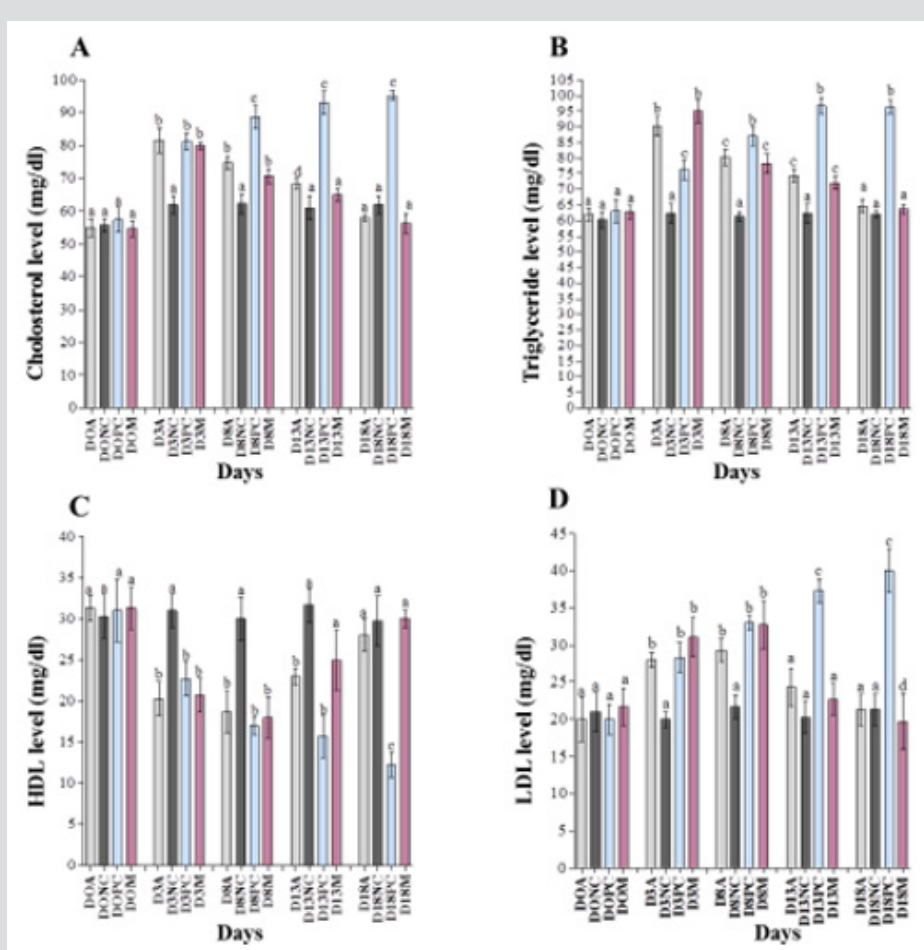

Figure 3: Analysis of blood of rabbits medicated with CW at dose rate of $2.2 \mathrm{~g} / \mathrm{kg}$. 


\section{Analysis of Triglyceride Level in Blood}

Measurement of blood triglyceride (TG) level of healthy rabbits observed $62.0 \pm 2.00,61.3 \pm 3.21,60.3 \pm 2.52,63.0 \pm 3.61,62.7 \pm 2.08$ $\mathrm{mg} / \mathrm{dl}$ in group A, B, C, D, and E, respectively (Figures 3B \& 4B). Analysis of STZ-induced diabetic rabbits confirmed that blood TG level was increased as compared to control. At day 3rd, the TG level of blood samples of diabetic rabbits increased to $90.3 \pm 3.21$, $91.0 \pm 2.65,76.3 \pm 3.21$, and $95.0 \pm 3.61 \mathrm{mg} / \mathrm{dl}$ for groups A, B, D, and E, as compared to negative control $62.3 \pm 3.06 \mathrm{mg} / \mathrm{dl}$ for group $\mathrm{C}$, respectively (Figures 3B \& 4B). Treating diabetic rabbits, A and B with CW at the dose rate of $2.2 \mathrm{~g} / \mathrm{kg}$ and $4.1 \mathrm{~g} / \mathrm{kg}$, and group E were treated with metformin at $14 \mathrm{mg} / \mathrm{kg}$, significantly reduced TG level to $80.3 \pm 2.52,79.3 \pm 1.53$, and $78.3 \pm 3.06 \mathrm{mg} / \mathrm{dl}$ as compared to positive control $87.0 \pm 3.00 \mathrm{mg} / \mathrm{dl}$ at day 8 th. With continuous treatment, TG levels were reduced to $74.3 \pm 2.08,73.0 \pm 3.61$ and $72.0 \pm 2.00 \mathrm{mg} /$ $\mathrm{dl}$ as compared to positive control96.7 $\pm 2.52 \mathrm{mg} / \mathrm{dl}$ after blood analysis at day 13th. At day 18th, further reduction was noted in TG level $(64.7 \pm 2.08,64.0 \pm 1.00$ and $63.7 \pm 1.53 \mathrm{mg} / \mathrm{dl})$ as compared to the day 13 th as shown in Figures 3B \& 4B. Therefore, it is concluded that $\mathrm{CW}$ at the dose rate of 2.2 and $4.1 \mathrm{~g} / \mathrm{kg}$ decreases TG level.

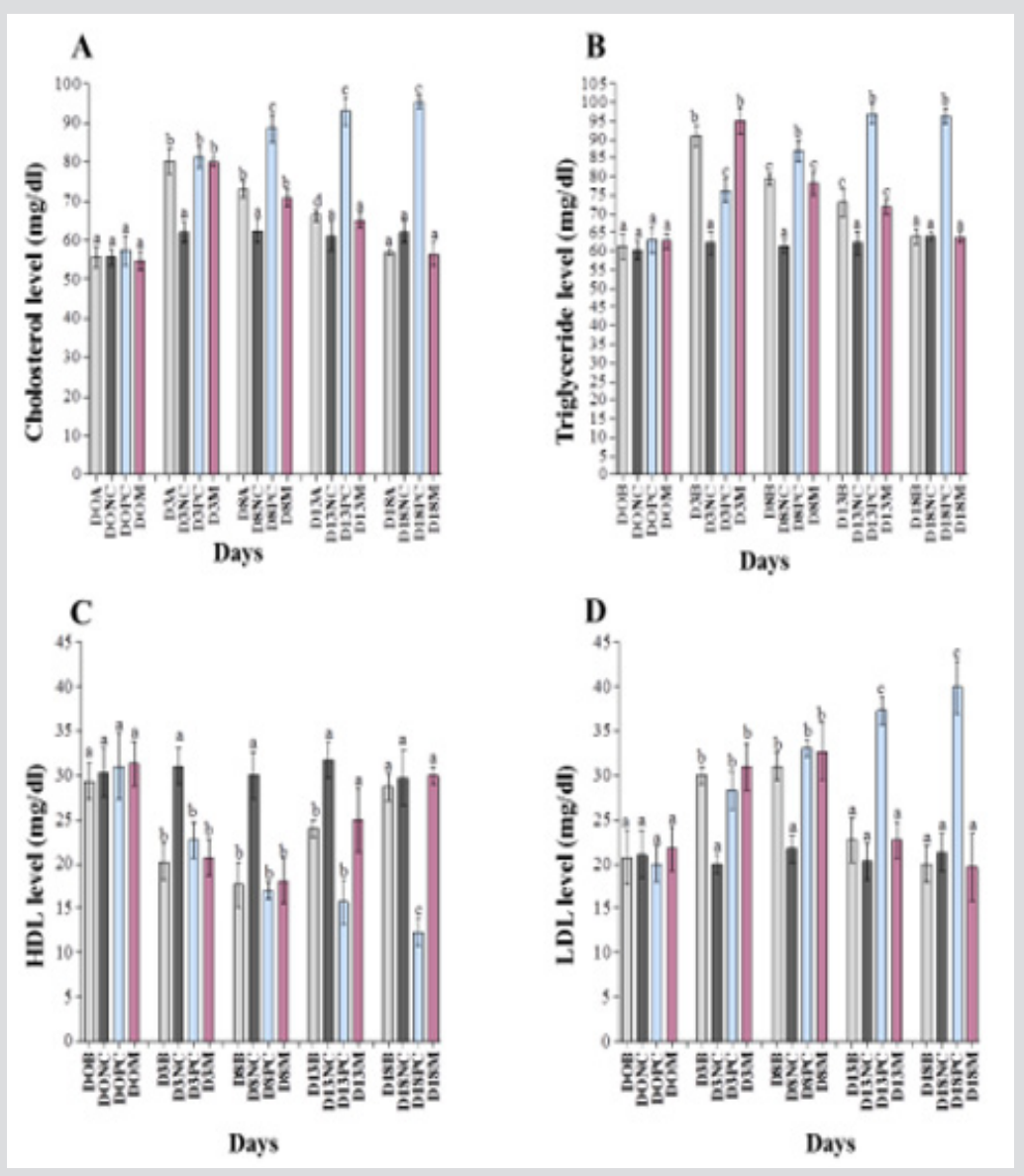

Figure 4: Analysis of blood of rabbits medicated with CW at dose rate of $4.1 \mathrm{~g} / \mathrm{kg}$.

\section{Evaluation of High-Density Lipoprotein (HDL) in blood}

Prior to diabetes induction, the blood high density lipoprotein (HDL) level of all the groups were measured as $31.3 \pm 1.53$, $29.3 \pm 2.08,30.3 \pm 1.53,31.0 \pm 2.65$, and $31.3 \pm 2.52 \mathrm{mg} / \mathrm{dl}$ for groups A, B, C, D, and E, respectively (Figures 3C \& 4C). At day 3rd of diabetes induction, the HDL level was reduced to $20.3 \pm 2.08,20.0 \pm 2.00$, $22.7 \pm 2.08$, and $20.7 \pm 2.08 \mathrm{mg} / \mathrm{dl}$ in diabetic group $\mathrm{A}, \mathrm{B}, \mathrm{D}$, and E. The blood HDL level of negative control C $(31.0 \pm 2.00 \mathrm{mg} / \mathrm{dl})$ remained unchanged. Our results demonstrated that $\mathrm{CW}$-treated rabbits (dose rate of $2.2 \mathrm{~g} / \mathrm{kg}$ and $4.1 \mathrm{~g} / \mathrm{kg}$ ) showed elevated level of blood HDL of $18.7 \pm 2.52$ and $17.7 \pm 2.52$. Analysis of and $14 \mathrm{mg} /$ $\mathrm{kg}$ of metformin-treated samples obtained $18.0 \pm 2.65 \mathrm{mg} / \mathrm{dl}$ HDL concentration at day 8.Further increase was observed in HDL level in the groups treated either with $\mathrm{CW}$ or metformin. At day 13th and 18th, the HDL level was increased to $23.0 \pm 1.00$ and 24.0 \pm 1.00 , and $28.0 \pm 2.00$ and $28.7 \pm 1.53$ for diabetic groups treated with $\mathrm{CW}$ at the dose rate of $2.2 \mathrm{~g} / \mathrm{kg}$ and $4.1 \mathrm{~g} / \mathrm{kg}$, respectively (Figures 3C \& 4C). Consistently, the metformin-treated groups showed $23.0 \pm 1.00$ and $28.0 \pm 2.00 \mathrm{mg} / \mathrm{dl}$ HDL concentration at day 13 and 18, respectively (Figures 3C \& 4C). So, we recommend that CW increases the blood HDL level of diabetic rabbits (Figures 3C \& 4C).

\section{Evaluation of Low-Density Lipoprotein (LDL) in Blood}

The healthy samples showed normal concentration of lowdensity lipoprotein (LDL) and obtained 20.0 $\pm 3.00,20.7 \pm 2.08$, $21.0 \pm 2.65,20.0 \pm 2.00,21.7 \pm 2.52 \mathrm{mg} / \mathrm{dl}$ for groups A, B, C, D, and 
E, respectively. After induction of diabetes at day 3rd, the LDL level was increased to $28.0 \pm 1.00,30.0 \pm 1.00,28.3 \pm 2.08$, and $31.0 \pm 2.65$ $\mathrm{mg} / \mathrm{dl}$ for groups $\mathrm{A}, \mathrm{B}, \mathrm{D}$, and $\mathrm{E}$, compare to negative control $20.0 \pm 1.00$, respectively as (Figures 3D \& 4D). Upon treatment with CW at the dose rate of $2.2 \mathrm{~g} / \mathrm{kg}$ and $4.1 \mathrm{~g} / \mathrm{kg}$, group $\mathrm{A}$ and $\mathrm{B}$ showed slightly low LDL level of $29.3 \pm 1.53,31.0 \pm 2.65$, respectively. In parallel, metformin-treated diabetic group (E) at the dose rate of $14 \mathrm{mg} / \mathrm{kg}$ obtained $32.7 \pm 3.21 \mathrm{mg} / \mathrm{dl}$. At day 8th, LDL level were decreased to $29.3 \pm 1.53,31.0 \pm 2.65,32.7 \pm 3.21 \mathrm{mg} / \mathrm{dl}$, as compared to positive control $33.0 \pm 1.00 \mathrm{mg} / \mathrm{dl}$. At day 13th, LDL levels were reduced in CW- as well as Metformin-treated groups to 24.3 \pm 2.52 , $22.7 \pm 2.52$, and $22.7 \pm 2.08 \mathrm{mg} / \mathrm{dl}$, respectively. At day 18 th, further decrease was recorded in LDL values in both the CW- as well as Metformin-treated groups to $21.3 \pm 2.08,20.0 \pm 2.00$, and $19.7 \pm 3.79$ $\mathrm{mg} / \mathrm{dl}$, respectively. Conversely, the LDL level remained higher for positive control $(40.0 \pm 3.00 \mathrm{mg} / \mathrm{dl})$ and lower for negative control $(21.3 \pm 2.08 \mathrm{mg} / \mathrm{dl})$ as shown in Figure 3D \& 4D. So, it is concluded that $\mathrm{CW}$ at the dose rate of $2.2 \mathrm{~g} / \mathrm{kg}$ and $4.1 \mathrm{~g} / \mathrm{kg}$ decreases LDL in diabetic rabbits (Figures 3D \& 4D).

\section{Discussion}

Diabetes mellitus (DM) can mainly be attributed to the sedentary life style and calorie-rich diet. DM is linked with abnormal lipid metabolism and is considered as a major factor for the development of atherosclerosis and cardiovascular complication [29]. STZ causes hyperlipidemia along with hyperglycemic condition [21,30,31] Previously, it was investigated that STZ causes diabetes by rapid depletion of beta-cells, which leads to reduction of insulin secretion [32]. In rats, intravenous injection of STZ (70 mg/ $\mathrm{kg}$ of body weight) induces diabetes mellitus [33]. Moreover, Mozaffari et al., induced DM in rats by injecting STZ at dose rate of $90 \mathrm{mg} / \mathrm{kg}$ of the body weight [31]. In present study, STZ was used as DM inducer at the dose rate of $80 \mathrm{mg} / \mathrm{kg}$ body weight. Our results confirmed that STZadministrated rabbits lost their body weights, which is the ultimate symptom of diabetic rabbits [34-36]. After treatment with CW at dose rate of $2.2 \mathrm{~g} / \mathrm{kg}$ and $4.1 \mathrm{~g} / \mathrm{kg}$, an increase occurred in the body weight of diabetic rabbits. Our results are in strong agreement of Preetha et al. and Saat et al. where they observed an increase the body weights of virgin coconut oil-treated diabetic rabbits $[37,38]$.

Additionally, administration of STZ $80 \mathrm{mg} / \mathrm{kg}$ increased the glucose level of STZ-administrated rabbits. Several reports have investigated that STZ administration increases blood glucose level upon reduction of insulin secretion $[34,39,40]$. Our study follows Aly et al. when they induced hyperglycemia by injecting STZ at a dose rate of $65 \mathrm{mg} / \mathrm{kg}$ body weight [41]. In another study, STZ increased blood glucose level when injected a at dose rate of 60 $\mathrm{mg} / \mathrm{kg}$ body weight [42]. Our results demonstrated that CW at the dose rate of $2.2 \mathrm{~g} / \mathrm{kg}$ and $4.1 \mathrm{~g} / \mathrm{kg}$ decreased blood glucose level of diabetic rabbits. Preetha et al. investigated that Albizia myriophylla and virgin coconut oil have significant hypoglycemic potential [37]. Additionally, a couple of studies have reported that mature coconut water and coconut kernel protein reduced the blood glucose level of diabetic rats $[38,43]$. Therefore, our study recommends that coconut water decreasedthe blood glucose level of diabetic rabbits. Our results observed elevated level of cholosterol in STZ-induced diabetic rabbits. Our results are in strong agreement that STZ accumulates high concentration of cholesterol diabetic rats [41,44].

We observed that CW reduced the blood cholesterol level of diabetic rabbits. Previously, palm kernel oil and coconut oil were used to reduce the total cholesterol levels of diabetic rats $[45,46]$. Our study also observed that diabetic rabbits were symptomized by elevated levels of triglycerides. Increase in triglyceride concentration is an essential indication of diabetic subjects [41,44,47]. Our study confirmed that $\mathrm{CW}$ caused a signifcant reduction in the concentration of triglyceride level of diabetic rabbits.Other studies have also reported that coconut oil and coconut water reduces triglyceride level and have anti-diabetic activities [45,46,48]. STZ administration decreases HDL levels in animals [30,44]. Our study observed that CWincreased HDL level in CW-treated rabbits. Same results werealsodocumented by several other reports [4850]. Finally, the present study investigated that STZ increased the LDL level STZ-intoxicated rabbits. STZ has been reported to cause a significant increase in LDL concentration which leads to DM $[41,44,51]$. Our study investigated that CW reduces LDL level in diabetic rabbits. other studies have also observed that coconut water was given to diabetic rats and same reduction in LDL level were found [48,52]. In another study, the synergistic effects of coconut oil and olive oil has demonstrated to reduce the LDL level [53]. Overall, our study demonstrated that CW has anti-diabetic potential and could be used as a nutraceutical or functional food for the management of diabetes and its associated complications.

\section{Conclusion}

STZ induced a characteristic multiphasic immediate response in rabbits. There was frequent urination, decreased physical activities and sluggishness in comparison to negative control. In addition, marked individual variations in response exist in terms of onset and severity of glycemic changes. The body weights were reduced in diabetic rabbits. There was also increase in cholesterol, triglyceride and low-density lipoprotein values in all the intoxicated rabbits with low values of high-density lipoprotein. After treatment with coconut water as well as metformin for two weeks, all the parameters became normal or near to normal when compared to positive control. Form the results of our study prove that coconut wateris effective against experimentally diabetic. The present work demonstrates that both concentrationsare capable of improving the diabetic complications. Conversely, coconut water showed an adverse effect in relation to the diabetic complications.

\section{References}

1. Narayan KV (2005) The diabetes pandemic: looking for the silver lining. Clinical diabetes 23: 51-53

2. Alberti KGMM, Zimmet PF (1998) Definition, diagnosis and classification of diabetes mellitus and its complications. Part 1: diagnosis and classification of diabetes mellitus. Provisional report of a WHO consultation. Diabetic medicine 15(7): 539-553. 
3. Fox CS, Coady S, Sorlie PD, D’Agostino RB, Pencina MJ, et al. (2007) Increasing cardiovascular disease burden due to diabetes mellitus the Framingham Heart Study. Circulation 115: 1544-1550.

4. Gavin III JR, Alberti K, Davidson MB, De Fronzo RA (1997) Report of the expert committee on the diagnosis and classification of diabetes mellitus. Diabetes care 20(7): 1183-1197.

5. Chatila R, West BA (1996) Hepatomegaly and abnormal liver tests due to glycogenosis in adults with diabetes. Medicine 75(6): 327-333.

6. Mc Cane D, Hanson RL, Charles MA, Jacobsson LT, Pettitt DD, et al. (1994) Comparison of tests for glycated haemoglobin and fasting and two-hour plasma glucose concentrations as diagnostic methods for diabetes. Bmj 308(6940): 1323-1328.

7. King H, Rewers M (1993) Global estimates for prevalence of diabetes mellitus and impaired glucose tolerance in adults. Diabetes care 16(1): 157-177.

8. Boyle JP, Honeycutt AA, Narayan KV, Hoerger TJ, Geiss LS, et al. (2001) Projection of diabetes burden through 2050 impact of changing demography and disease prevalence in the US. Diabetes care 24(11): 1936-1940.

9. Benjamin SM, Valdez R, Geiss LS, Rolka DB, Narayan KV (2003) Estimated Number of Adults With Prediabetes in the US in 2000 Opportunities for prevention. Diabetes care 26(3): 645-649.

10. Shaw JE, Sicree RA, Zimmet PZ (2010) Global estimates of the prevalence of diabetes for 2010 and 2030. Diabetes research and clinical practice 87(1): 4-14.

11. Mathers CD, Loncar D (2006) Projections of global mortality and burden of disease from 2002 to 2030. Plos med 3(1): e442.

12. Khan MA, Sultan SM, Nazli R, Akhtar T, Khan MA, et al. (2014) Depression among patients with type-II diabetes mellitus. J Coll Physicians Surg Pak 24(10): 770-771.

13. Meo SA, Zia I, Bukhari IA, Arain SA (2016) Type 2 diabetes mellitus in Pakistan: Current prevalence and future forecast. JPMA. The Journal of the Pakistan Medical Association 66(12): 1637-1642.

14. Jones D (2011) Diabetes field cautiously upbeat despite possible setback for leading SGLT2 inhibitor. Nature Publishing Group.

15. Egan JM, Bulotta A, Hui H, Perfetti R (2003) GLP-1 receptor agonists are growth and differentiation factors for pancreatic islet beta cells. Diabetes/metabolism research and reviews 19(2): 115-123.

16. Kim MJ, Han JY, Shin JY, Kim SI, Lee JM, et al. (2015) Metformin-associated lactic acidosis: predisposing factors and outcome. Endocrinology and Metabolism 30(1): 78-83.

17. Mudaliar M, FACE Sunder Chang M, Anna R, Henry M, Robert R (2003) Thiazolidinediones, peripheral edema, and type 2 diabetes: incidence, pathophysiology, and clinical implications. Endocrine Practice 9(5): 406-416.

18. Vasilakou D, Karagiannis T, Athanasiadou E, Mainou M, Liakos A, et al (2013) Sodium-glucose cotransporter 2 inhibitors for type 2 diabetes: a systematic review and meta-analysis. Annals of internal medicine 159(4) 262-274.

19. Al Jamal AR, Ibrahim A (2011) Effects of olive oil on lipid profiles and blood glucose in type2 diabetic patients. Int J Diabetes Metab 19: 19-22.

20. Sachdewa A, Khemani L (2003) Effect of Hibiscus rosa sinensis Linn. ethanol flower extract on blood glucose and lipid profile in streptozotocin induced diabetes in rats. Journal of Ethnopharmacology 89(1): 61-66.

21. Rajasekaran S, Ravi K, Sivagnanam K, Subramanian S (2006) Beneficial effects of Aloe vera leaf gel extract on lipid profile status in rats with streptozotocin diabetes. Clinical and Experimental Pharmacology and Physiology 33(3): 232-237.

22. Singab ANB, El Beshbishy HA, Yonekawa M, Nomura T, Fukai T (2005) Hypoglycemic effect of Egyptian Morus alba root bark extract: effect on diabetes and lipid peroxidation of streptozotocin-induced diabetic rats. Journal of ethnopharmacology 100(3): 333-338.
23. Yong JW, Ge L, Ng YF, Tan SN (2009) The chemical composition and biological properties of coconut (Cocos nucifera L.) water. Molecules 14(12): 5144-5164

24. Nwangwa EK (2012) The reno-protective effects of coconut water on the kidneys of diabetic wistar rats. Journal of Health Science 2(1): 1-4.

25. Bhagya D, Prema L, Rajamohan T (2010) Beneficial effects of tender coconut water on blood pressure and lipid levels in experimental hypertension. Journal of cell and tissue research 10: 2139.

26. Prathapan A, Rajamohan T (2011) Antioxidant and antithrombotic activity of tender coconut water in experimental myocardial infarction. Journal of Food Biochemistry 35(5): 1501-1507.

27. Ruiz SMA, Bernad MJB, Chacón SDCC, Estrada DV (2018) Glucose Response in Animals Induced With Experimental Diabetes Type 1 after Treatment with Human Insulin Exposed To High Temperatures. Transylvanian Review 1.

28. Saleem Mir M, Maqbool Darzi M, Musadiq Khan H, Ahmad Kamil S, Hassan Sofi A, et al. (2014) Pre-diabetic clinical changes induced by low doses of alloxan-streptozotocin cocktail in rabbits. Iranian Journal of Pathology 9(2): 197-112.

29. Biddinger SB, Kahn CR (2006) From mice to men: insights into the insulin resistance syndromes. Annu Rev Physiol 68: 123-158.

30. Chattopadhyay R, Bandyopadhyay M (2005) Effect of Azadirachta indica leaf extract on serum lipid profile changes in normal and streptozotocin induced diabetic rats. African Journal of Biomedical Research 8: 101104.

31. Emam MA (2012) Comparative evaluation of antidiabetic activity of Rosmarinus officinalis $L$. and Chamomile recutita in streptozotocin induced diabetic rats. Agric Biol J North Am 3(6): 247.

32. Weir G, Clore E, Zmachinski C, Bonner Weir S (1981) Islet secretion in a new experimental model for non-insulin-dependent diabetes. Diabetes 30(7): 590-595.

33. Karunanayake EH, Hearse DJ, Mellows G (1975) The metabolic fate and elimination of streptozotocin. Portland Press Limited 3(3): 410-414.

34. Adeyemi DO, Komolafe OA, Adewole OS, Obuotor EM, Adenowo TK (2009) Anti hyperglycemic activities of Annona muricata (Linn) 6(1): 62-69.

35. Cortright RN, Collins HL, Chandler MP, Lemon PW, DiCARLO SE (1996) Diabetes reduces growth and body composition more in male than in female rats. Physiology \& behavior 60(5): 1233-1238.

36. Yoshida T, Nishioka H, Nakamura Y, Kondo M (1985) Reduced noradrenaline turnover in streptozotocin-induced diabetic rats. Diabetologia 28(9): 692-696.

37. Saat A, Rosali R, Syakroni N (2013) Potential hypoglycemic property of Albizia myriophylla and virgin coconut oil in streptozotocin induced diabetic rats. Int J Pharm Pharm Sci 5(4): 199-202.

38. Preetha P, Devi VG, Rajamohan T (2012) Hypoglycemic and antioxidant potential of coconut water in experimental diabetes. Food \& function 3(7): 753-757.

39. Habibuddin M, Daghriri HA, Humaira T, Al Qahtani MS, Hefzi AAH (2008) Antidiabetic effect of alcoholic extract of Caralluma sinaica L. on streptozotocin-induced diabetic rabbits. Journal of ethnopharmacology 117(2): 215-220

40. Motyl K, Mc Cabe LR (2009) Streptozotocin, type I diabetes severity and bone. Biological procedures online 11: 296-315.

41. Aly HF, Ebrahim ME, Metawaa HM, Hosni EAmA, Ebrahim FM (2010) In vitro and in vivo evaluation of the antidiabetic effect of different extracts of Nepeta cataria in streptozotocin induced diabetic rats. J Am Sci 6(10): 364-386.

42. El Sayyed H, Badawy G, Elnabi SH, El Elaimy I, Al Shehari E (2015) Ameliorative effect of Morus alba leaves extract against developmental retinopathy in pups of diabetic and aluminum intoxicated pregnant albino rats. Asian Pacific Journal of Tropical Biomedicine 5(4): 300-309. 
43. Salil G, Nevin K, Rajamohan T (2011) Arginine rich coconut kerne protein modulates diabetes in alloxan treated rats. Chemico-biological interactions 189(2): 107-111.

44. Adewole S, Caxton Martins E, Ojewole J (2006) Histochemcal and biochemical effects of melatonin on pancreatic $\beta$-cells of streptozotocintreated diabetic rats. Pharmacologyonline.

45. Kiitchevsky D, Tepper SA, Lloyd LM, Davidson LM, Klurfeld DM (1988) Serum and liver lipids of rats fed cocoa butter, corn oil, palm kernel oil, coconut oil and cholesterol. Nutrition research 8(3): 287-294.

46. Nevin K, Rajamohan T (2008) Influence of virgin coconut oil on blood coagulation factors, lipid levels and LDL oxidation in cholesterol fed Sprague-Dawley rats. e-SPEN, the European e-Journal of Clinical Nutrition and Metabolism 3(1): e1-e8.

47. Lenich CM, Chobanian AV, Brecher P, Zannis V (1991) Effect of dietary cholesterol and alloxan-diabetes on tissue cholesterol and apolipoprotein E mRNA levels in the rabbit. Journal of lipid research 32(3): 431-438.

48. Preetha P, Devi VG, Rajamohan T (2014) Antihyperlipidemic effects of mature coconut water and its role in regulating lipid metabolism in

\section{ISSN: 2574-1241}

DOI: 10.26717/BJSTR.2019.16.002884

Ayaz Ali Khan, Amir Zeb. Biomed J Sci \& Tech Res

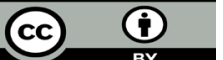

This work is licensed under Creative

Commons Attribution 4.0 License

Submission Link: https://biomedres.us/submit-manuscript.php alloxan-induced experimental diabetes. Comparative Clinical Pathology 23(5): 1331-1337.

49. Naskar S, Mazumder UK, Pramanik G, Gupta M, Kumar RS, et al (2011) Evaluation of antihyperglycemic activity of Cocos nucifera Linn. on streptozotocin induced type 2 diabetic rats. Journal of ethnopharmacology 138(8): 769-773.

50. Marina A, Man YC, Amin I (2009) Virgin coconut oil: emerging functional food oil. Trends in Food Science \& Technology 20(10): 481-487.

51. Brunzell JD, Ayyobi AF (2003) Dyslipidemia in the metabolic syndrome and type 2 diabetes mellitus. The American journal of medicine 115(1): $24-28$

52. Eyres L, Eyres MF, Chisholm A, Brown RC (2016) Coconut oil consumption and cardiovascular risk factors in humans. Nutrition reviews 74(4): 267 280.

53. Nagaraju A, Lokesh BR (2007) Interesterified coconut oil blends with groundnut oil or olive oil exhibit greater hypocholesterolemic effects compared with their respective physical blends in rats. Nutrition research 27(9): 580-586.

$\begin{array}{ll}\text { BIOMEDICAL } & \text { Assets of Publishing with us } \\ \text { RESEARCHES } & \text { - Global archiving of articles } \\ \text { ISSN: } 2574-1241 & \text { Immediate, unrestricted online access } \\ \end{array}$

